\title{
Dietas para Leitões em Aleitamento e Pós-Desmame ${ }^{1}$
}

\section{Vanusa Patrícia de Araújo Ferreira ${ }^{2}$, Aloízio Soares Ferreira ${ }^{3}$, Juarez Lopes Donzele ${ }^{3}$, Luiz Fernando Teixeira Albino ${ }^{3}$, Paulo Cezar Gomes ${ }^{3}$, Paulo Roberto Cecon ${ }^{4}$, Alexandre de Oliveira Teixeira ${ }^{5}$}

\begin{abstract}
RESUMO - Duzentos leitões mestiços (Landrace $\times$ Large White) foram distribuídos em delineamento em blocos ao acaso, com quatro tratamentos e cinco repetições, com o objetivo de avaliar os efeitos de diferentes dietas sobre o desempenho e os pesos relativos e absolutos de fígado e pâncreas de leitões durante os períodos de aleitamento e pós-desmame, arraçoados dos 14 a 56 dias de idade. Os tratamentos consistiram de quatro dietas, as quais foram fornecidas aos animais dos 14 aos 42 dias de idade, quando então foram substituídas por uma dieta simples (ração de creche). Com base nos resultados, pode-se concluir que dietas contendo fontes de proteína de alta qualidade, como leite em pó integral e farinha de peixe, sem fonte suplementar de alimentos energéticos, como soro de leite, quando fornecidas a leitões dos 14 aos 42 dias de idade, proporcionaram os mesmos resultados de desempenho de leitões desmamados aos 28 dias de idade e recebendo rações simples à base de milho e farelo de soja.
\end{abstract}

Palavras-chave: dietas complexas, dietas simples, peso dos órgãos, suínos

\section{Diets for Piglets in Suckling and Post-Weaning Periods}

\begin{abstract}
Two hundred crossbred piglets (Landrace $\times$ Large White), fed in the period from 14 to 56 days of age, were assigned to a randomized block design with four treatments and five replicates, to evaluate the effects of different diets on the piglets performance, relative and absolute weights of liver and pancreas in suckling and post-weaning periods. The treatments consisted of four diets, that were supplied from 14 to 42 days of age, when were replaced by a simple diet (nursing ration). The results allowed to conclude that all diets containing sources of hight protein quality, like integral dried milk and fish meal, withouth supplementary source of energetic foods, like dried whey when supplied pigs from 14 days to 42 days of age, provide the same results for the pigs weaned to the 28 days of age and receiving simple diets with corn and soybean meal.
\end{abstract}

Key Words: complex diets, simple diets, swines, weight organs

\section{Introdução}

A redução do período de aleitamento, prática que visa elevar o número de partos por porca por ano, com considerável redução no custo de produção, tornou-se grande desafio para os nutricionistas, pois para efetuá-la com eficiência é necessário o estabelecimento de combinação perfeita de ingredientes, bem como o conhecimento da biodisponibilidade dos nutrientes, de modo a reduzir ou evitar problemas pós- desmame (TRINDADE NETO et al., 1994), tendo-se em vista que o sistema digestivo do leitão recém-nascido está naturalmente adaptado ao leite da porca, e a troca deste alimento por outro alimento ou outro sistema de alimentação, no caso de desmame precoce, pode associar-se a distúrbios gastrointestinais e depressão no crescimento (FERREIRA et al., 1988).
Assim, tem sido prática comum fornecer, aos leitões em aleitamento, dietas formuladas com ingredientes de alto valor biológico, principalmente os protéicos, contendo altos teores de nutrientes (proteína, lisina e energia), a partir do sétimo ou décimo dia após o parto. A justificativa do uso dessa prática baseia-se no fato de que consumo de ração precoce pode estimular o desenvolvimento do sistema enzimático digestivo, favorecendo melhor aproveitamento das dietas (FERREIRA et al., 1992). Tem-se sugerido, também, que a ingestão de pequenas quantidades de certas proteínas antes do desmame pode sensibilizar o sistema imune do animal, de forma que haja reação de hipersensibilidade (alérgica), quando o animal ingere maiores quantidades da mesma proteína depois do desmame; como resultado pode ocorrer lesão intestinal, que pode

\footnotetext{
1 Tese apresentada à Universidade Federal de Viçosa, pelo primeiro autor, como um dos requisitos para obtenção do mestrado em Zootecnia, projeto financiado pelo CNPq.

2 Estudante de Doutorado DZO/UFMG, cep 30161-970-Belo Horizonte, MG. E.mail: vanpaf@hotmail.com

3 Professor do DZO/UFV, Campus Universitário, cep 30571-000-Viçosa, MG.

4 Professor Adjunto do DPI/UFV, Campus Universitário, cep 30571-000-Viçosa, MG.

5 Estudante de Doutorado DZO/UFV, cep 30571-000-Viçosa, MG.
} 
provocar diarréia alimentar ou deixar o intestino mais susceptível à proliferação de microorganismos patogênicos, dando origem a diarréias infecciosas (BERTO et al., 1996).

A partir de resultados de pesquisa, tem-se verificado que o consumo de dieta pelos leitões, antes dos 21 dias de idade, tem sido pequeno, menos de $10 \mathrm{~g}$ por dia (LOPES et al., 1986; LUCAS e LODGE, 1961). Assim, na tentativa de aumentar o consumo de ração pelos leitões, antes do desmame, e melhorar a qualidade da ração, visando melhores resultados de desempenho, têm-se estudado outras alternativas alimentares, bem como outros ingredientes ou combinações protéicas.

O fornecimento de rações complexas contendo fontes protéicas de origem animal e vegetal tem sido estudado na expectativa de que juntas possam proporcionar melhoria na digestibilidade dos nutrientes das dietas, principalmente aminoácidos, em função do melhor balanceamento entre eles. Resultados satisfatórios com o uso de rações complexas foram obtidos por LEPINE et al. (1991) e TOKACH et al. (1994); contudo, CRENSHAW et al. (1986) e RAMALHO (1990) não verificaram melhorias no desempenho dos leitões com o uso de rações complexas.

Assim, verificou-se que há dúvidas quanto ao tipo de dieta a ser usada, em função da idade de desmame, e aos efeitos sobre a saúde e o desempenho dos leitões, em função do uso de dietas inadequadas na maternidade e na creche. Portanto, o presente experimento foi realizado com o objetivo de estudar os efeitos e as conseqüências do uso de diferentes tipos de dietas sobre desempenho, composição de carcaça e peso de fígado e pâncreas de leitões em aleitamento e pós-desmame, arraçoados no período de 14 a 56 dias de idade.

\section{Material e Métodos}

O experimento foi conduzido nos galpões experimentais de maternidade e creche do Setor de Suinocultura do Departamento de Zootecnia da Universidade Federal de Viçosa.

Foram utilizados 200 leitões provenientes de 25 leitegadas mestiças (Landrace $\times$ Large White), os quais foram equalizados entre as porcas em experimento com delineamento em blocos casualizados, com quatro tratamentos e cinco repetições, adotando-se como critérios de escolha dos animais o peso da leitegada e o grau de parentesco, sendo o restante descartado do experimento. Na maternidade, a unidade experimental constituiu-se de uma leitegada equalizada em dez animais.

Para a escolha das porcas para cobertura, adotouse ordem de partos, em torno, de quatro por porca.

Os tratamentos aplicados dos 14 aos 42 dias de idade foram:

A) Dieta composta por milho, farinha de peixe e leite em pó, com $18 \%$ de proteína bruta.

B) Dieta simples composta por milho e farelo de soja, com $18 \%$ de proteína bruta.

C) Dieta composta por milho, farelo de soja, farinha de peixe e leite em pó, com $18 \%$ de proteína bruta.

D) Dieta simples composta por milho, farelo de soja e farelo de trigo, com $16 \%$ de proteína bruta.

Estas dietas eram isoprotéicas, isolisínicas e isocalóricas, com exceção da dieta $\mathrm{D}$ (ração de lactação), e foram formuladas para atender às exigências dessa categoria animal, segundo (ROSTAGNO et al. 1994). Por outro lado, em razão do alto nível de inclusão (20\%) da farinha de peixe na ração $\mathrm{A}$, esta ficou com os níveis de Ca e P muito acima das demais, sendo superior às recomendações de ROSTAGNO et al. (1994), e das exigências dos animais.

Dos 42 aos 56 dias de idade, as dietas experimentais (tratamentos) foram substituídas por uma dieta à base de milho e farelo de soja, com $18 \%$ de proteína bruta, $0,95 \%$ de lisina, $3400 \mathrm{kcal}$ de energia digestível (ração de creche), que foi formulada para atender às exigências da fase, segundo recomendações de ROSTAGNO et al. (1994).

As composições centesimal e bromatológica das dietas utilizadas no período experimental e na creche são apresentadas na Tabela 1. As análises químicas das mesmas foram conduzidas no Laboratório de Nutrição Animal do Departamento de Zootecnia da Universidade Federal de Viçosa, segundo metodologia descrita por SILVA (1990).

Após o desmame, que ocorreu aos 28 dias de idade, oito animais de cada leitegada (quatro machos castrados e quatro fêmeas) foram transferidos para creches constituídas de gaiolas metálicas suspensas medindo $1,60 \times 1,00 \times 0,56 \mathrm{~m}$, com pisos e laterais telados, dotados de comedouros semi-automáticos e bebedouros tipo chupeta, tendo sido adotado o peso médio como critério para a escolha dos animais, de modo que oito animais com pesos mais próximos da média da leitegada foram escolhidos.

Os animais foram pesados ao nascer, aos 14, 21, 28,42 e 56 dias de idade, para verificar o ganho de peso individualmente, enquanto o consumo de ração 
Rev. bras. zootec.

Tabela 1 - Composição centesimal das dietas experimentais

Table 1 - Composition of experimental diets

\begin{tabular}{|c|c|c|c|c|c|}
\hline \multirow[b]{2}{*}{$\begin{array}{l}\text { Ingredientes }(\%) \\
\text { Ingredients }(\%)\end{array}$} & \multicolumn{4}{|c|}{$\begin{array}{c}\text { Dietas experimentais } \\
\text { Experimental diets }\end{array}$} & \multirow[b]{2}{*}{$\begin{array}{c}\text { Creche } \\
\text { Nursing ration } \\
\end{array}$} \\
\hline & A & B & $\mathrm{C}$ & $\mathrm{D}$ & \\
\hline $\begin{array}{l}\text { Milho } \\
\text { Corn }\end{array}$ & 66,49 & 68,90 & 65,25 & 60,50 & 68,10 \\
\hline $\begin{array}{l}\text { Farelo de soja } \\
\text { Soyabean meal }\end{array}$ & - & 25,90 & 14,50 & 20,51 & 26,90 \\
\hline $\begin{array}{l}\text { Farelo de trigo } \\
\text { Wheat meal }\end{array}$ & - & - & - & 9,90 & - \\
\hline $\begin{array}{l}\text { Farinha de peixe } \\
\text { Fish meal }\end{array}$ & 20,00 & - & 8,10 & - & - \\
\hline $\begin{array}{l}\text { Leite em pó integral } \\
\text { Integral dried milk }\end{array}$ & 8,50 & - & 7,00 & - & - \\
\hline $\begin{array}{l}\text { Açúcar } \\
\text { Sugar }\end{array}$ & - & - & - & 2,00 & - \\
\hline $\begin{array}{l}\text { Óleo de soja } \\
\text { Soybean oil }\end{array}$ & 0,91 & 1,16 & 1,00 & 3,59 & 1,33 \\
\hline $\begin{array}{l}\text { Calcário } \\
\text { Limestone }\end{array}$ & 0,50 & 0,96 & 0,80 & 1,13 & 0,97 \\
\hline $\begin{array}{l}\text { Fosfato bicálcico } \\
\text { Dicalcium phosphate }\end{array}$ & - & 1,90 & 0,10 & 1,65 & 1,85 \\
\hline $\begin{array}{l}\text { Sal } \\
\text { Salt }\end{array}$ & 0,41 & 0,41 & 0,41 & 0,50 & 0,41 \\
\hline $\begin{array}{l}\text { L-lisina } \mathrm{HCl}(96 \%) \\
\text { L-lysine } \mathrm{HCl}(96 \%)\end{array}$ & - & 0,43 & 0,23 & - & 0,02 \\
\hline $\begin{array}{l}\text { DL-Metionina }(99 \%) \\
\text { DL-Methionine }(99 \%)\end{array}$ & - & 0,10 & - & - & 0,15 \\
\hline $\begin{array}{l}\text { Premix vitamínico } \\
\text { Vitamin premix }^{1}\end{array}$ & 0,12 & 0,12 & 0,12 & 0,12 & 0,12 \\
\hline $\begin{array}{l}\text { Premix mineral }^{2} \\
\text { Mineral premix }^{2}\end{array}$ & 0,10 & 0,10 & 0,10 & 0,10 & 0,10 \\
\hline $\begin{array}{l}\text { Material inerte } \\
\text { Inert material }\end{array}$ & 2,95 & - & 2,37 & - & 0,03 \\
\hline $\begin{array}{l}\text { Bacitracina de zinco } \\
\text { Zinc bacitracin }\end{array}$ & 0,02 & 0,02 & $\begin{array}{l}0,02 \\
\text { sição ca } \\
\text { tted com }\end{array}$ & - & 0,02 \\
\hline $\begin{array}{l}\text { Proteína bruta }(\%) \\
\text { Crude protein }(\%)\end{array}$ & 18,00 & 18,02 & 18,08 & 16,00 & 18,00 \\
\hline $\begin{array}{l}\text { Energia digestível }(\mathrm{kcal} / \mathrm{kg}) \\
\text { Digestive energy }(\mathrm{kcal} / \mathrm{kg})\end{array}$ & 3400 & 3400 & 3400 & 3400 & 3400 \\
\hline $\begin{array}{l}\text { Fósforo total (\%) } \\
\text { Total phosphorus (\%) }\end{array}$ & 1,11 & 0,64 & 0,67 & 0,63 & 0,63 \\
\hline $\begin{array}{l}\text { Fósforo disponível (\%) } \\
\text { Available phosphorus }\end{array}$ & 0,74 & 0,43 & 0,41 & 0,40 & 0,42 \\
\hline $\begin{array}{l}\text { Cálcio }(\%) \\
\text { Calcium }(\%)\end{array}$ & 1,53 & 0,90 & 0,97 & 0,90 & 0,90 \\
\hline $\begin{array}{l}\text { Sódio }(\%) \\
\text { Sodium }(\%)\end{array}$ & 0,25 & 0,20 & 0,23 & 0,23 & 0,20 \\
\hline $\begin{array}{l}\text { Lisina }(\%) \\
\text { Lysine }(\%)\end{array}$ & 1,30 & 1,27 & 1,30 & 0,80 & 0,96 \\
\hline $\begin{array}{l}\text { Met + Cis }(\%) \\
\text { Meth + Cys }(\%)\end{array}$ & 0,83 & 0,69 & 0,69 & 0,52 & 0,72 \\
\hline $\begin{array}{l}\text { Metionina (\%) } \\
\text { Methionine (\%) }\end{array}$ & 0,52 & 0,40 & 0,38 & 0,25 & 0,42 \\
\hline $\begin{array}{l}\text { Treonina }(\%) \\
\text { Threonine }(\%)\end{array}$ & 0,83 & 0,69 & 0,77 & 0,62 & 0,71 \\
\hline $\begin{array}{l}\text { Triptofano (\%) } \\
\text { Tryptophan (\%) }\end{array}$ & 0,25 & 0,23 & 0,25 & 0,21 & 0,23 \\
\hline
\end{tabular}


por animal foi verificado pela diferença entre as quantidades fornecidas e as sobras de ração por baia, auferidas aos 28, 42 e 56 dias de idade dos animais, divididas pelo número de animais por baia em cada fase. A conversão alimentar foi obtida, dos 28 aos 42 e dos 42 aos 56 dias de idade, dividindo-se o consumo pelo ganho nos respectivos períodos.

Aos 14 dias de idade, foi abatido um leitão de cada leitegada e, aos 28, 42 e 56 dias de idade, dois leitões de cada tratamento e de cada repetição, perfazendo um total de 140 animais sacrificados.

Os leitões foram abatidos por sangramento, com jejum prévio de ração de 12 horas e fornecimento normal de água, depilados com lança-chamas e eviscerados. O fígado e o pâncreas de cada animal foram retirados da carcaça e imediatamente pesados a fim de calcular os pesos absolutos e relativos aos 28, 42 e 56 dias de idade.

As carcaças inteiras, incluindo cabeça e pés, foram pesadas e trituradas, durante 15 minutos, em "Cutter" comercial de 30 HP e 1775 revoluções por minuto; após homogeneização, foram retiradas amostras de aproximadamente um quilo, que foram, então, estocadas em freezer a $-12^{\circ} \mathrm{C}$, para posteriores análises laboratoriais.

Os teores de proteína e gordura das amostras foram obtidos por intermédio da metodologia descrita por SILVA (1990).

As deposições de proteína e gordura nas carcaças foram calculadas pelas diferenças entre as composições de carcaças dos leitões no início de cada período e as obtidas no final.

Os dados de desempenho e deposições de proteína e gordura nas carcaças, e os pesos absoluto e relativo do fígado e pâncreas dos animais foram analisados utilizando-se o programa SAEG (UNIVERSIDADE FEDERAL DE VIÇOSA - UFV, 1982). As médias foram comparadas pelo teste Newman-Keuls, a 5\% de probabilidade.

\section{Resultados e Discussão}

Não foi verificado efeito $(\mathrm{P}>0,05)$ das dietas (Tabela 2) sobre o peso inicial e final, o ganho de peso diário, o ganho de peso total e as deposições de proteína e gordura na carcaça dos animais durante $o$ período de 14 a 28 dias de idade, o que provavelmente pode ser atribuído ao baixo consumo de ração $(\mathrm{P}<0,05)$ dos animais, que, segundo FOWLER (1981), tem pouco significado biológico antes de três semanas de idade, pois, mesmo com dietas mais complexas, têm-se obser- vado consumos sempre inferiores a 5,0 g/leitão/dia.

Não foi verificado efeito $(\mathrm{P}>0,05)$ das dietas sobre nenhuma das variáveis estudadas durante os períodos de 14 a 42 dias de idade (Tabela 3 ) e nem dos 28 aos 42 dias de idade (Tabela 4), mas os pesos finais médios dos animais no período de 28 a 42 dias de idade podem ser considerados baixos (7736 a $8312 \mathrm{~g}$ ), devido ao peso baixo aos 28 dias, o que pode ser atribuído ao baixo consumo médio de ração (3598 a $3752 \mathrm{~g}$ ) durante o período de 14 dias pós-desmame. Estes resultados de desempenho podem ser explicados pelo provável estresse imunológico ao qual os animais foram submetidos, por consequiência do desmame, diminuindo consideravelmente o consumo de ração e, conseqüentemente, o ganho de peso desses animais. Além disso, outros fatores ligados às rações experimentais podem ter contribuído para os baixos consumo e desempenho dos animais, como a composição das rações (ausência de fonte de lactose, acúcar, acidificante, palatabilizante, entre outros), o excesso de farinha de peixe (dieta A, principalmente), assim como os níveis nutricionais utilizados. Estes resultados foram semelhantes aos encontrados por RAMALHO (1990), que testou dietas simples e complexas e concluiu que o consumo de ração, o ganho de peso diário, a conversão alimentar e a utilização da proteína não foram estatisticamente significativos a $5 \%$ de probabilidade para os dois tipos de dieta.

As dietas não apresentaram diferenças significativas para as deposições de proteína e gordura na carcaça dos animais nos dois períodos, mas pode-se observar que houve queda drástica em relação às observadas no período de 14 a 28 dias de idade, talvez em função do baixo ganho de peso, que pode ter ocorrido em virtude da substituição de uma dieta à base de leite e altamente digestível por uma dieta sólida e de menor digestibilidade, conforme destacado por FREITAS et al. (1995), e em razão de a primeira semana pós-desmame ser a fase mais crítica, pois os leitões passam por várias mudanças no que tange ao processo digestivo. Por outro lado, a dieta $\mathrm{D}$ apresentou numericamente maiores deposições de proteína e gordura na carcaça dos animais no período de 28 a 42 dias de idade. Provavelmente, houve maior deposição de gordura na carcaça dos animais, devido ao fato de a relação energia/ proteína ter sido superior nesse tratamento.

Não foi verificado efeito $(\mathrm{P}>0,05)$ da dieta de creche sobre nenhuma das variáveis estudadas (Tabela 5), durante o período de 42 a 56 dias de idade, 
Rev. bras. zootec.

Tabela 2 - Desempenho, deposição de proteína e gordura na carcaça de leitões, alimentados com as dietas experimentais, no período de 14 a 28 dias de idade

Table 2 - Performance, deposition of protein and fat in the carcasses of piglets, fed with experimentals diets, during the period of 14 at 28 days of age

\begin{tabular}{|c|c|c|c|c|c|}
\hline \multirow[b]{2}{*}{$\begin{array}{l}\text { Ingredientes }(\%) \\
\text { Ingredients }(\%)\end{array}$} & \multicolumn{5}{|c|}{$\begin{array}{l}\text { Dieta experimental } \\
\text { Experimental diets }\end{array}$} \\
\hline & $\mathrm{A}$ & $\mathrm{B}$ & $\mathrm{C}$ & $\mathrm{D}$ & $\mathrm{CV}(\%)$ \\
\hline \multicolumn{6}{|l|}{ Peso inicial médio (g) (14 dias) } \\
\hline Initial weight mean $(g)$ (14 days) & $3190^{\mathrm{a}}$ & $3198^{a}$ & $3180^{\mathrm{a}}$ & $3192^{\mathrm{a}}$ & 0,42 \\
\hline Peso final médio (g) (28 dias) & $5288^{\mathrm{a}}$ & $5878^{a}$ & $5265^{\mathrm{a}}$ & $5596^{\mathrm{a}}$ & 4,38 \\
\hline \multicolumn{6}{|l|}{ Final weight mean $(g)$ (28 days) } \\
\hline Consumo de ração (g/dia) & $3,0^{\mathrm{ab}}$ & $4,0^{\mathrm{ab}}$ & $2,2^{b}$ & $5,2^{\mathrm{a}}$ & 40,33 \\
\hline Ration intake (g/day) & & & & & \\
\hline $\begin{array}{l}\text { Ganho de peso total }(\mathrm{g}) \\
\text { Total weight gain }(\mathrm{g})\end{array}$ & $2173^{\mathrm{a}}$ & $2531^{\mathrm{a}}$ & $2256^{\mathrm{a}}$ & $2318^{\mathrm{a}}$ & 13,96 \\
\hline $\begin{array}{l}\text { Ganho de peso (g/dia) } \\
\text { Weight gain (g/day) }\end{array}$ & $155^{\mathrm{a}}$ & $190^{\mathrm{a}}$ & $149^{\mathrm{a}}$ & $170^{\mathrm{a}}$ & 10,42 \\
\hline & & & $\begin{array}{l}\text { sição na } \\
\text { tion in th }\end{array}$ & & \\
\hline $\begin{array}{l}\text { Proteína }(\mathrm{g} / \mathrm{dia}) \\
\text { Protein }(\mathrm{g} / \text { day })\end{array}$ & $19,0^{\mathrm{a}}$ & $18,2^{\mathrm{a}}$ & $19,2^{\mathrm{a}}$ & $16,2^{\mathrm{a}}$ & 21,19 \\
\hline $\begin{array}{l}\text { Gordura (g/dia) } \\
\text { Fat (g/day) }\end{array}$ & $10,3^{\mathrm{a}}$ & $14,5^{\mathrm{a}}$ & $12,2^{\mathrm{a}}$ & $10,9^{\mathrm{a}}$ & 32,17 \\
\hline $\begin{array}{l}\text { Relação de deposição } \\
\text { (gordura/proteína) } \\
\text { Relation of deposition } \\
\text { (fat/protein) }\end{array}$ & 0,54 & 0,80 & 0,64 & 0,67 & \\
\hline
\end{tabular}

Médias, na mesma linha, seguidas de letras diferentes diferem $(P<0,05)$ pelo teste Newman-Keuls.

Dieta A - farinha de peixe e leite em pó (18\% PB); dieta B - farelo de soja (18\% PB); dieta C - farelo de soja, farinha de peixe e leite em pó (18\% $\mathrm{PB})$; e dieta $\mathrm{D}$ - farelo de soja e farelo de trigo (16\% PB).

Means, in the same line, fllowed by the diferents letters differ $(P>.05)$ by the Newman-Keuls test.

Diet $A$ - Fish meal and dried milk (18\% CP); diet B - soyabean meal (18\% CP); diet C - soyabean meal, fish meal and dried milk (18\% CP); and diet $D$ - soyabean meal and wheat meal $(16 \% C P)$.

exceto na deposição de gordura na carcaça, tendo a dieta $\mathrm{D}$ proporcionado 43,$2 ; 31,4$; e $31,4 \%$ mais deposição de gordura em relação às dietas $\mathrm{A}, \mathrm{B}$ e $\mathrm{C}$, respectivamente. Estes resultados podem ser atribuídos ao maior nível de inclusão de óleo de soja na dieta que, segundo CLOSE e STANIER (1984), pode aumentar a deposição de gordura na carcaça. Contudo, notou-se que o consumo dos animais que receberam a dieta $\mathrm{B}$ no período anterior ( $\operatorname{dos} 28$ aos 42 dias de idade) foi $7,3 \%$ maior em relação ao consumo da dieta A. Assim, constata-se que houve ganho compensatório dos animais, no período de 42 a 56 dias de idade, submetidos à dieta A no período anterior, uma vez que foram os que obtiveram menores ganhos de peso na fase anterior e maiores ganhos de peso na fase subseqüente. Resultados contrários foram obtidos por MASCARENHAS (1997), que não verificou a ocorrência de ganho de peso compensatório dos 42 aos 63 dias de idade para os animais submetidos à dieta complexa dos 21 aos 42 dias de idade.
Estes resultados estão de acordo com os de MEADE et al. (1969), que não observaram diferenças estatísticas no desempenho dos animais na fase inicial, quando foram alimentados com dietas simples e complexas contendo diferentes níveis de proteína. Resultados semelhantes foram encontrados por BERTO et al. (1997), quando testaram dietas simples e complexas, fornecidas na fase inicial a leitões desmamados aos 28 dias de idade. Com relação à deposição de proteína nesta fase, não foram verificadas diferenças $(\mathrm{P}>0,05)$ entre os tratamentos, embora os animais submetidos ao tratamento $\mathrm{D}$ tenham apresentado superioridade de 14,2 e $29,7 \%$ em relação aos das dietas B e C, em que os consumos de proteína bruta foram similares.

Quanto aos pesos absolutos e relativos de fígado (Tabela 6), não se verificou a influência das dietas sobre o peso do órgão, aos 28 e aos 42 dias de idade, mas aos 56 dias de idade foi encontrado efeito $(\mathrm{P}<0,05)$, sendo que os animais provenientes da dieta A apresentaram pesos absolutos de fígado com valo- 
FERREIRA et al.

Tabela 3 - Desempenho, consumos de proteína bruta (PB) e energia digestível (ED) e deposições de proteína e gordura na carcaça de leitões alimentados com as dietas experimentais, no período de 14 a 42 dias de idade

Table 3 - Performance, crude protein (CP) and digestible energy (DE) intakes and protein and fat depositions in the carcass of piglets fed experimentals diets, from 14 to 42 days of age

\begin{tabular}{|c|c|c|c|c|c|}
\hline \multirow[b]{2}{*}{$\begin{array}{l}\text { Ingredientes (\%) } \\
\text { Ingredients }(\%)\end{array}$} & \multicolumn{4}{|c|}{ Dieta experimental (Experimental diet) } & \multirow[b]{2}{*}{$\mathrm{CV}(\%)$} \\
\hline & $\mathrm{A}$ & B & $\mathrm{C}$ & $\mathrm{D}$ & \\
\hline $\begin{array}{l}\text { Peso inicial médio }(\mathrm{g})(14 \text { dias }) \\
\text { Average initial weight }(\mathrm{g})(14 \text { days })\end{array}$ & $3190^{\mathrm{a}}$ & $3198^{\mathrm{a}}$ & $3180^{\mathrm{a}}$ & $3192^{\mathrm{a}}$ & 0,42 \\
\hline $\begin{array}{l}\text { Peso final médio (g) (42 dias) } \\
\text { Average final weight (g) (42 days) }\end{array}$ & $7736^{\mathrm{a}}$ & $8312^{\mathrm{a}}$ & $8303^{\mathrm{a}}$ & $8129^{a}$ & 5,73 \\
\hline $\begin{array}{l}\text { Consumo de ração (g/dia) } \\
\text { Feed intake (g/day) }\end{array}$ & $260^{\mathrm{a}}$ & $271^{\mathrm{a}}$ & $265^{\mathrm{a}}$ & $273^{\mathrm{a}}$ & 5,10 \\
\hline $\begin{array}{l}\text { Ganho de peso total }(\mathrm{g}) \\
\text { Total weight gain }(\mathrm{g})\end{array}$ & $4542^{\mathrm{a}}$ & $5102^{\mathrm{a}}$ & $5124^{\mathrm{a}}$ & $4934^{\mathrm{a}}$ & 9,66 \\
\hline $\begin{array}{l}\text { Ganho de peso (g/dia) } \\
\text { Weight gain (g/day) }\end{array}$ & $162^{\mathrm{a}}$ & $188^{\mathrm{a}}$ & $175^{\mathrm{a}}$ & $178^{\mathrm{a}}$ & 7,72 \\
\hline $\begin{array}{l}\text { Conversão alimentar } \\
\text { Feed/gain ratio }\end{array}$ & $1,60^{\mathrm{a}}$ & $1,50^{\mathrm{a}}$ & $1,45^{\mathrm{a}}$ & $1,56^{\mathrm{a}}$ & 8,07 \\
\hline $\begin{array}{l}\text { Consumo de } \mathrm{PB}(\mathrm{g} / \mathrm{dia}) \\
\text { CP intake }(\mathrm{g} / \text { day })\end{array}$ & $47^{\mathrm{a}}$ & $49^{a}$ & $47^{\mathrm{a}}$ & $44^{\mathrm{a}}$ & 6,10 \\
\hline $\begin{array}{l}\text { Consumo de ED (kcal/dia) } \\
\text { DE intake (kcal/day) }\end{array}$ & $885^{\mathrm{a}}$ & $922^{\mathrm{a}}$ & $900^{\mathrm{a}}$ & $930^{\mathrm{a}}$ & 5,13 \\
\hline & Dep & ão na carc & eposition $i$ & carcass) & \\
\hline $\begin{array}{l}\text { Proteína (g/dia) } \\
\text { Protein (g/day) }\end{array}$ & $31,6^{\mathrm{a}}$ & $29,8^{\mathrm{a}}$ & $35,1^{\mathrm{a}}$ & $33,4^{\mathrm{a}}$ & 23,08 \\
\hline $\begin{array}{l}\text { Gordura }(g / d i a) \\
\text { Fat }(g / d a y)\end{array}$ & $17,6^{\mathrm{a}}$ & $21,1^{\mathrm{a}}$ & $19,1^{\mathrm{a}}$ & $20,5^{\mathrm{a}}$ & 22,60 \\
\hline $\begin{array}{l}\text { Relação de deposição (gordura/proteína) } \\
\text { Fat/protein deposition ratio }\end{array}$ & 0,56 & 0,71 & 0,54 & 0,61 & \\
\hline
\end{tabular}

Médias seguidas de letras iguais não diferem $(\mathrm{P}>0,05)$ pelo teste Newman-Keuls (Means followed by the same line do not differ [P>.05] by Newman-Keuls test).

Tabela 4 - Desempenho, consumos de proteína bruta (PB) e energia digestível (ED) e deposições de proteína e gordura na carcaça de leitões alimentados com as dietas experimentais, no período de 28 a 42 dias de idade

Table 4 - Performance, crude protein (CP) and digestible energy $(D E)$ intakes and protein and fat depositions in the carcass of piglets fed experimentals diets, from 28 to 42 days of age

\begin{tabular}{|c|c|c|c|c|c|}
\hline \multirow[b]{2}{*}{$\begin{array}{l}\text { Ingredientes }(\%) \\
\text { Ingredients }(\%)\end{array}$} & \multicolumn{4}{|c|}{ Dieta experimental (Experimental diets) } & \multirow[b]{2}{*}{$\mathrm{CV}(\%)$} \\
\hline & A & B & $\mathrm{C}$ & $\mathrm{D}$ & \\
\hline Peso inicial médio (g) (28 dias) & $5290^{\mathrm{a}}$ & $5745^{\mathrm{a}}$ & $5437^{\mathrm{a}}$ & $5557^{\mathrm{a}}$ & 5,93 \\
\hline $\begin{array}{l}\text { Peso final médio (g) (42 dias) } \\
\text { Average final weight ( } g \text { ) (42 days) }\end{array}$ & $7736^{\mathrm{a}}$ & $8312^{\mathrm{a}}$ & $8303^{\mathrm{a}}$ & $8129^{\mathrm{a}}$ & 5,73 \\
\hline $\begin{array}{l}\text { Consumo de ração (g/dia) } \\
\text { Feed intake (g/day) }\end{array}$ & $257^{\mathrm{a}}$ & $267^{\mathrm{a}}$ & $262^{\mathrm{a}}$ & $268^{\mathrm{a}}$ & 5,35 \\
\hline $\begin{array}{l}\text { Ganho de peso total }(\mathrm{g}) \\
\text { Total weight gain }(\mathrm{g})\end{array}$ & $2492^{\mathrm{a}}$ & $2590^{\mathrm{a}}$ & $2881^{\mathrm{a}}$ & $2570^{\mathrm{a}}$ & 10,74 \\
\hline $\begin{array}{l}\text { Ganho de peso (g/dia) } \\
\text { Weight gain (g/day) }\end{array}$ & $177^{\mathrm{a}}$ & $186 \mathrm{a}$ & $205^{\mathrm{a}}$ & $184^{\mathrm{a}}$ & 11,19 \\
\hline $\begin{array}{l}\text { Conversão alimentar } \\
\text { Feed/gain ratio }\end{array}$ & $1,44^{\mathrm{a}}$ & $1,45^{\mathrm{a}}$ & $1,27^{\mathrm{a}}$ & $1,48^{\mathrm{a}}$ & 9,94 \\
\hline $\begin{array}{l}\text { Consumo de PB (g/dia) } \\
\text { CP intake (g/day) }\end{array}$ & $46^{\mathrm{a}}$ & $48^{\mathrm{a}}$ & $46^{\mathrm{a}}$ & $43^{\mathrm{a}}$ & 6,43 \\
\hline $\begin{array}{l}\text { Consumo de ED (kcal/dia) } \\
\text { DE intake ( } k \text { cal/day) }\end{array}$ & $875^{\mathrm{a}}$ & $908^{\mathrm{a}}$ & $892^{\mathrm{a}}$ & $912^{\mathrm{a}}$ & 5,38 \\
\hline $\begin{array}{l}\text { Proteína (g/dia) } \\
\text { Protein (g/dav) }\end{array}$ & $12,5^{\mathrm{a}}$ & $\begin{array}{c}\text { ão na carc } \\
11,6^{\mathrm{a}}\end{array}$ & $\begin{array}{l}15,9^{\mathrm{a}} \\
\end{array}$ & $\begin{array}{l}\text { cass) } \\
17,3^{\mathrm{a}}\end{array}$ & 36,55 \\
\hline $\begin{array}{l}\text { Gordura (g/dia) } \\
\text { Fat }(g / \text { day })\end{array}$ & $7,36^{\mathrm{a}}$ & $6,62^{\mathrm{a}}$ & $6,96^{\mathrm{a}}$ & $9,58^{\mathrm{a}}$ & 39,07 \\
\hline $\begin{array}{l}\text { Relação de deposiç̧ão (gordura/proteína) } \\
\text { Fat/protein deposition ratio }\end{array}$ & 0,58 & 0,57 & 0,44 & 0,55 & \\
\hline
\end{tabular}


Rev. bras. zootec.

Tabela 5 - Desempenho, consumo de proteína bruta (PB) e energia digestível (ED) e deposições de proteína e de gordura na carcaça de leitões alimentados com as dietas experimentais, no período de 42 a 56 dias de idade

Table 5 - Performance, crude protein (CP) and digestible energy (DE) intake and protein and fat depositions in the carcass of piglets fed experimentals diets, from 42 to 56 days of age

\begin{tabular}{|c|c|c|c|c|c|}
\hline \multirow[b]{2}{*}{$\begin{array}{l}\text { Ingredientes(\%) } \\
\text { Ingredients (\%) }\end{array}$} & \multicolumn{4}{|c|}{ Dieta experimental (Experimental diet) } & \multirow[b]{2}{*}{$\mathrm{CV}(\%)$} \\
\hline & $\mathrm{A}$ & B & $\mathrm{C}$ & $\mathrm{D}$ & \\
\hline $\begin{array}{l}\text { Peso inicial médio }(\mathrm{g}) \text { (42 dias) } \\
\text { Average initial weight }(\mathrm{g})(42 \text { days })\end{array}$ & $7736^{\mathrm{a}}$ & $8311^{\mathrm{a}}$ & $8303^{\mathrm{a}}$ & $8128^{\mathrm{a}}$ & 5,73 \\
\hline $\begin{array}{l}\text { Peso final médio (g) ( } 56 \text { dias) } \\
\text { Average final weight ( } g \text { ) (56 days) }\end{array}$ & $12.330^{\mathrm{a}}$ & $13.055^{\mathrm{a}}$ & $12.698^{\mathrm{a}}$ & $12.765^{\mathrm{a}}$ & 5,28 \\
\hline $\begin{array}{l}\text { Consumo de ração (g/dia) } \\
\text { Feed intake (g/day) }\end{array}$ & $639^{\mathrm{a}}$ & $686^{\mathrm{a}}$ & $684^{\mathrm{a}}$ & $685^{\mathrm{a}}$ & 7,60 \\
\hline $\begin{array}{l}\text { Ganho de peso total }(\mathrm{g}) \\
\text { Total weight gain }(\mathrm{g})\end{array}$ & $4486^{\mathrm{a}}$ & $4874^{\mathrm{a}}$ & $4477^{\mathrm{a}}$ & $4799^{\mathrm{a}}$ & 9,31 \\
\hline $\begin{array}{l}\text { Ganho de peso (g/dia) } \\
\text { Weight gain (g/day) }\end{array}$ & $331^{\mathrm{a}}$ & $344^{\mathrm{a}}$ & $316^{\mathrm{a}}$ & $343^{\mathrm{a}}$ & 9,32 \\
\hline $\begin{array}{l}\text { Conversão alimentar } \\
\text { Feed/gain ratio }\end{array}$ & $2,03^{\mathrm{a}}$ & $1,98^{\mathrm{a}}$ & $2,14^{\mathrm{a}}$ & $2,00^{\mathrm{a}}$ & 5,86 \\
\hline $\begin{array}{l}\text { Consumo de } \mathrm{PB}(\mathrm{g} / \mathrm{dia}) \\
\text { CP intake }(\mathrm{g} / \text { day })\end{array}$ & $115^{\mathrm{a}}$ & $123^{\mathrm{a}}$ & $123^{\mathrm{a}}$ & $121^{\mathrm{a}}$ & 8,04 \\
\hline $\begin{array}{l}\text { Consumo de ED (kcal/dia) } \\
\text { DE intake (kcal/day) }\end{array}$ & $2173^{\mathrm{a}}$ & $2334^{\mathrm{a}}$ & $2326^{\mathrm{a}}$ & $2328^{\mathrm{a}}$ & 7,61 \\
\hline & & ição na carc & Deposition in & arcass) & \\
\hline $\begin{array}{l}\text { Proteína }(\mathrm{g} / \text { dia }) \\
\text { Protein }(g / \text { day })\end{array}$ & $29,5^{\mathrm{a}}$ & $36,7^{\mathrm{a}}$ & $32,3^{a}$ & $41,9^{\mathrm{a}}$ & 20,18 \\
\hline $\begin{array}{l}\text { Gordura (g/dia) } \\
\text { Fat }(\text { g/day) }\end{array}$ & $23,4^{\mathrm{b}}$ & $25,5^{\mathrm{ab}}$ & $25,5^{\mathrm{ab}}$ & $33,5^{\mathrm{a}}$ & 19,75 \\
\hline $\begin{array}{l}\text { Relação de deposição (gordura/proteína) } \\
\text { Fat/protein deposition ratio }\end{array}$ & 0,80 & 0,69 & 0,79 & 0,80 & \\
\hline
\end{tabular}

Médias, na mesma linha, seguidas de letras diferentes diferem pelo teste Newman-Keuls $(P<0,05)$.

Means, in the same line, followed by diferent letters differ ( $P>.05)$ by Newman-Keuls test.

Tabela 6 - Pesos absoluto e relativo do fígado e pâncreas de leitões aos 28, 42 e 56 dias de idade, alimentados com dietas experimentais

Table 6 - Absolute and relative weights of liver and pancreas of piglets fed with experimentals diets at 28, 42 and 56 days of age

\begin{tabular}{|c|c|c|c|c|c|}
\hline \multirow{4}{*}{$\begin{array}{l}\text { Parâmetro } \\
\text { Parameter }\end{array}$} & \multirow{2}{*}{\multicolumn{4}{|c|}{$\begin{array}{c}\text { Dieta experimental } \\
\text { Experimental diet }\end{array}$}} & \multirow{4}{*}{$\mathrm{CV}(\%)$} \\
\hline & & & & & \\
\hline & A & B & $\mathrm{C}$ & $\mathrm{D}$ & \\
\hline & \multicolumn{4}{|c|}{$\begin{array}{l}\text { Fígado }(\mathrm{g}) \\
\text { Liver }(\mathrm{g})\end{array}$} & \\
\hline 28 dias de idade (absoluto) (relativo) & $168^{\mathrm{a}}$ & $177^{\mathrm{a}}$ & $169^{\mathrm{a}}$ & $171^{\mathrm{a}}$ & 7,65 \\
\hline 28 days of age (absolute) (relative) & $3,2^{\mathrm{a}}$ & $3,1^{\mathrm{a}}$ & $3,1^{\mathrm{a}}$ & $3,1^{\mathrm{a}}$ & 5,73 \\
\hline 42 dias de idade (absoluto) (relativo) & $232^{\mathrm{a}}$ & $278^{\mathrm{a}}$ & $259^{\mathrm{a}}$ & $262^{\mathrm{a}}$ & 11,32 \\
\hline 42 days of age (absolute) (relative) & $3,0^{\mathrm{a}}$ & $3,3^{\mathrm{a}}$ & $3,1^{\mathrm{a}}$ & $3,2^{\mathrm{a}}$ & 9,64 \\
\hline 56 dias de idade (absoluto) (relativo) & $360^{\mathrm{b}}$ & $416^{\mathrm{a}}$ & $420^{\mathrm{a}}$ & $420^{\mathrm{a}}$ & 6,26 \\
\hline \multirow[t]{2}{*}{56 days of age (absolute) (relative) } & $2,8^{b}$ & $3,2^{\mathrm{a}}$ & $3,3^{\mathrm{a}}$ & $3,3^{\mathrm{a}}$ & 5,96 \\
\hline & \multicolumn{4}{|c|}{$\begin{array}{l}\text { Pâncreas (g) } \\
\text { Pancreas }(g)\end{array}$} & \\
\hline 28 dias de idade (absoluto) (relativo) & $19^{a}$ & $11^{\mathrm{a}}$ & $11^{\mathrm{a}}$ & $10^{\mathrm{a}}$ & 57,9 \\
\hline 28 days of age (absolute) (relative) & $0,38^{\mathrm{a}}$ & $0,19^{\mathrm{a}}$ & $0,21^{\mathrm{a}}$ & $0,18^{\mathrm{a}}$ & 64,84 \\
\hline 42 dias de idade (absoluto) (relativo) & $13^{\mathrm{a}}$ & $16^{\mathrm{ab}}$ & $19 b$ & $19^{\mathrm{b}}$ & 17,4 \\
\hline 42 days of age(absolute) (relative) & $0,17^{\mathrm{a}}$ & $0,20^{\mathrm{a}}$ & $0,23^{\mathrm{a}}$ & $0,23^{\mathrm{a}}$ & 18,35 \\
\hline 56 dias de idade (absoluto) (relativo) & $29^{a}$ & 29 & $30^{\mathrm{a}}$ & $34^{\mathrm{a}}$ & 10,5 \\
\hline 56 days of age (absolute) (relative) & $0,23^{\mathrm{b}}$ & $0,22^{b}$ & $0,24^{\mathrm{b}}$ & $0,27^{\mathrm{a}}$ & 7,57 \\
\hline
\end{tabular}

Médias, na mesma linha, seguidas de letras diferentes diferem pelo teste Newman-Keuls $(P<0,05)$.

Means, in the same line, followed by different letters differ $(P>$.05) by Newman-Keuls test. 
res variando de 15,5 a 16,7\% menores em relação aos que receberam as dietas $\mathrm{B}, \mathrm{C}$ e $\mathrm{D}$ e pesos relativos de fígado $17,8 \%$ menores em comparação aos que receberam a dieta $\mathrm{D}$. Este fato pode ter ocorrido em função de menores consumos de proteína bruta e energia digestível.

Com relação aos pesos absolutos de pâncreas (Tabela 6), não foi verificado efeito $(\mathrm{P}>0,05)$ das dietas sobre o peso de pâncreas aos 28 e aos 42 dias de idade, mas aos 56 dias de idade houve diferença $(\mathrm{P}<0,05)$, sendo a dieta $\mathrm{D}$ (fornecida no período de 14 a 42 dias de idade) a que proporcionou maior desenvolvimento do órgão.

\section{Conclusões}

Dietas contendo fontes de proteína de alta qualidade, como leite em pó integral e farinha de peixe, sem fonte suplementar de alimentos energéticos, como soro de leite, quando fornecidas a leitões dos 14 aos 42 dias de idade, proporcionaram os mesmos resultados de desempenho de leitões desmamados aos 28 dias de idade e recebendo rações simples à base de milho e farelo de soja.

\section{Referências Bibliográficas}

BERTO, D.A., KRONKA, R.N., SANTOS, H.S.L.et al. 1996. Efeito do período de fornecimento de ração semi-complexa na fase inicial, sobre o ganho de peso compensatório nas fases de crescimento e terminação. R. Soc. Bras. Zootec., 25(4):671-682.

BERTO, D., KRONKA, R.N., THOMAZ, M.C. et al. 1997. Efeitos do tipo de dieta e do sistema de alimentação na fase inicial sobre o desempenho de leitões. R. Soc. Bras. Zootec., 26(1):144-152.

CLOSE, W.H., STANIER, M.W. 1984. Effects of plane of nutrition and environmental temperature on the growth and development of the early-weaned piglet. Anim. Prod., 38(2):221-231.

CRENSHAW, T.D., COOK, M.E., COLE, J. 1986. Effect of nutritional status, age at weaning and room temperature on growth and systemic immune response of weanling pigs. J. Anim. Sci., 63(6):1845-1853.

FERREIRA, A.S., COSTA, P.M.A., GOMES, J.C. et al. 1988. Desaparecimento da ingesta, $\mathrm{pH}$ estomacal e duodenal e formação de coágulos de leites de porca e de vaca e de extrato de soja no estômago e intestino delgado de leitões. $R$. Soc. Bras. Zootec., 17(3):308-316.

FERREIRA, A.S., SOBESTIANSKY, J.J., LIMA, G.J.M.M. et al. 1992. Início de arraçoamento e dietas para leitões lactentes. Desempenho na maternidade e na creche. R. Soc. Bras. Zootec., 21(5):847-854.

FOWLER, V.R. 1981. Recent advanced in animal nutrition. London: Butterwoerths. 141p.

FREITAS, H.T., FERREIRA, A.S., LUDWIG, A. Manejo de desmame precoce de leitões. REUNIÃO ANUAL DA SOCIEDADE BRASILEIRA DE ZOOTECNIA, 32, 1995, Brasília, DF. Anais... Brasília: SBZ, 1995. p.432-433.
LEPINE, A.J., MAHAN, D.C., CHUNG, Y.K. 1991. Growth performance of weanling pig fed corn-soy bean meal diets with or without dried whey at various L-lysine- $\mathrm{HCl}$ levels. J. Anim. Sci., 69:2026-2032.

LOPES, D.C., DONZELE, J.L., ALVARENGA, J.C. et al. 1986. Avaliação de épocas do início do arraçoamento de leitões em aleitamento. R. Soc. Bras. Zootec., 15(3):219-223.

LUCAS, E.A.M., LODGE, G.A. 1961. The nutrition of the young pig. 22 ed. Bucksburn Aberdeen Scotland, Rowett Research Institute. $199 \mathrm{p}$.

MASCARENHAS, A.G. Dietas simples com diferentes niveis protéicos e complexas fornecidas a leitões desmamados aos 21 dias de idade. Viçosa: UFV, 1997.40p. Dissertação (Mestrado em Zootecnia) - Universidade Federal de Viçosa, 1997.

MEADE, R.J., DUKELOW, W.R., GRANT, R.S. et al. 1969. Influence of age at weaning and kind and protein content of starter on rate and efficiency of gain of growing swine, and carcass characteristics. J. Anim. Sci., 29(2):309-319.

OWSLEY, W.F., ORR, D.E., TRIBBLE, LF. 1986. Effects of nitrogen and energy source on nutrient digestibility in the young pig. J. Anim. Sci., 63:492-496.

RAMALHO, I.V.O. Diferentes tipos de dietas para leitões desmamados aos 21 dias de idade. Lavras, ESAL, 1990.47p. Dissertação (Mestrado em Zootecnia) - Universidade Federal de Lavras, 1990.

ROSTAGNO, H.S., SILVA, D.J., COSTA, P.M.A.et al. 1994. Composição de alimentos e exigências nutricionais de aves e suínos; tabelas brasileiras. Viçosa - MG: UFV. 59p.

SILVA, D.J. 1990. Análise de alimentos (Métodos químicos e biológicos). Viçosa - MG: UFV. 165p.

SILVA, F.C.O., DONZELE, J.L., FREITAS, R.T.F. Digestibilidade e metabolizabilidade da energia de rações com diferentes níveis de óleo de soja para suínos. In: REUNIÃO ANUAL DA SOCIEDADE BRASILEIRA DE ZOOTECNIA, 34, 1998, Botucatu, SP. Anais... Botucatu: SBZ, 1998. p.472-474.

TOKACH, M.D., GOODBAND, R.D., NELSSEN, J.L. 1994. Recent developments in nutrition for the early-weaned pig. Comp. Cont. Educ. Prot. Vet., 16(3):407-419.

TRINDADE NETO, M.A.T., LIMA, J.A.F., BERTECHINI, A.G. 1994. Dietas e níveis protéicos para leitões desmamados aos 28 dias de idade - fase inicial. R. Soc. Bras. Zootec., 23(1):92-99.

UNIVERSIDADE FEDERAL DE VIÇOSA - UFV. 1982. Central de Processamento de Dados - UFV - CPD. SAEG Sistema para análise estatística e genética. Viçosa, MG. 59p.
Recebido em: $12 / 06 / 00$ Aceito em: 22/01/01 